\title{
PERMIAN MAYFLY NYMPHS
}

\author{
By Jarmila Kukalová* \\ Charles University, Prague
}

Although adult mayflies are not infrequently found in the fossil state, nymphs have been very rarely collected. The few fossil nymphs which are known have been placed in six families, four of them extant (Siphlonuridae, Leptophlebiidae, Ephemerellidae and Baetidae), and two extinct (Hexagenitidae and Misthodotidae). Three of the existing families are known in the geological record only from these nymphs. The Leptophlebiidae are known from the Pliocene of Australia (genus Atalophlebia, doubtfully determined) and from the Jurassic of the Soviet Union (Mesobaetis) and the Oligocene of Colorado (also Mesobaetis). The Baetidae are known from the Pliocene of Australia (Cloeon) and the Ephemerellidae from the Jurassic of China (Turfinella) and the Jurassic of the Soviet Union (Mesoneta). Since, as noted above, these three families are known as fossils only by the nymphs, the family determinations are probably not very reliable. One existing family, Siphlonuridae, is known from the Jurassic of the Soviet Union and is represented by wing fragments and nymphs (Stackelbergisca, Tshernova, 1967). The extinct family Hexagenitidae, known only from the Jurassic of Siberia, is represented by adults as well as nymphs (Ephemeropsis). The adults are well-known and have been fully described (Tshernova, I961) but the nymphs are less satisfactorily known. The Misthodotidae, known from Lower Permian deposits in North America and the Soviet Union, is represented by adults and a single, fragmentary nymph (Tshernova, I965). Finally, mention should be made of two extinct genera, Dyadentomum and Phthartus, both based on nymphs from the Permian of the Soviet Union, but so little-known that they have not been placed in any family (familiae incertae). ${ }^{1}$

The present paper deals with the first well-known Permian rep-

* Currently Alexander Agassiz Lecturer in Zoology, Museum of Comparative Zoology, Harvard University. This research has been aided by Grant No. GB 7308 from the National Science Foundation (F. M. Carpenter, Principal Investigator).

I am deeply indebted to Professor Carpenter, who suggested this study and was extremely helpful in its preparation.

${ }^{1}$ A species of Phthartus has been described from the Triassic of South Africa but its assignment to that genus is most questionable (Haughton, 1924). 
resentatives of mayfly nymphs, which are, in fact, the only known fossil nymphs of the order showing details of wing and body structure. In the course of many years of collecting in Lower Permian deposits in Moravia (Boskovice Furrow, Obora), I have been able to find only six specimens of mayfly nymphs (or their cast cuticles) and three nymphal wings. Since some of these specimens showed features of unusual interest, I brought them with me to make a further study while at the Museum of Comparative Zoology. Professor F. M. Carpenter, observing my specimens, turned over to me for study the few specimens of nymphs which he had collected in Lower Permian beds in Oklahoma (see Carpenter, 1947). Since these provide supplementary information, they have been included in this study. As will be shown below, the wing pads turn out to have been quite differently attached to the thorax in the Permian nymphs from the way in which they are attached in living nymphs. All but one of these Permian nymphs belong to the family Protereismatidae, the most primitive of all known mayflies with the exception of the Carboniferous Triplosoba, which is represented by only a single specimen of an adult (Carpenter, ig63).

My arrival at Harvard University came at an opportune moment, since Professor Carpenter was in the process of studying some fossil nymphs from the Upper Carboniferous (Pennsylvanian) nodules of Illinois. These turned out to belong to the Megasecoptera and to possess wing pads that were attached to the thorax much as in the protereismatid mayfly nymphs. The account of these megasecopterous nymphs is also being published in this issue of Psyche.

Most of the fossil mayfly nymphs discussed below apparently consist of the cast cuticle. This accounts for the distortion of the body, as shown in the drawings; in most cases the abdomen is bent at an abrupt angle away from the longitudinal axis of the thorax. It also explains the composite nature of the fossils; the dorsal and ventral surfaces having been pressed together in the process of preservation have left impressions of the structural details of both surfaces on each of the counterparts. It has proven almost impossible to distinguish between the dorsal and ventral structures in the case of the abdominal and thoracic segments. For this reason, I have included in the drawings all of the structures which are preserved, even although some of these were undoubtedly on the dorsal surface of the original nymph and some on the ventral surface; furthermore, as is usually done, I have used both the obverse and the reverse parts of the fossil in preparing the illustrations. The clarity of the wing venation in some of the nymphal wings is surprising. In some cases, the veins 


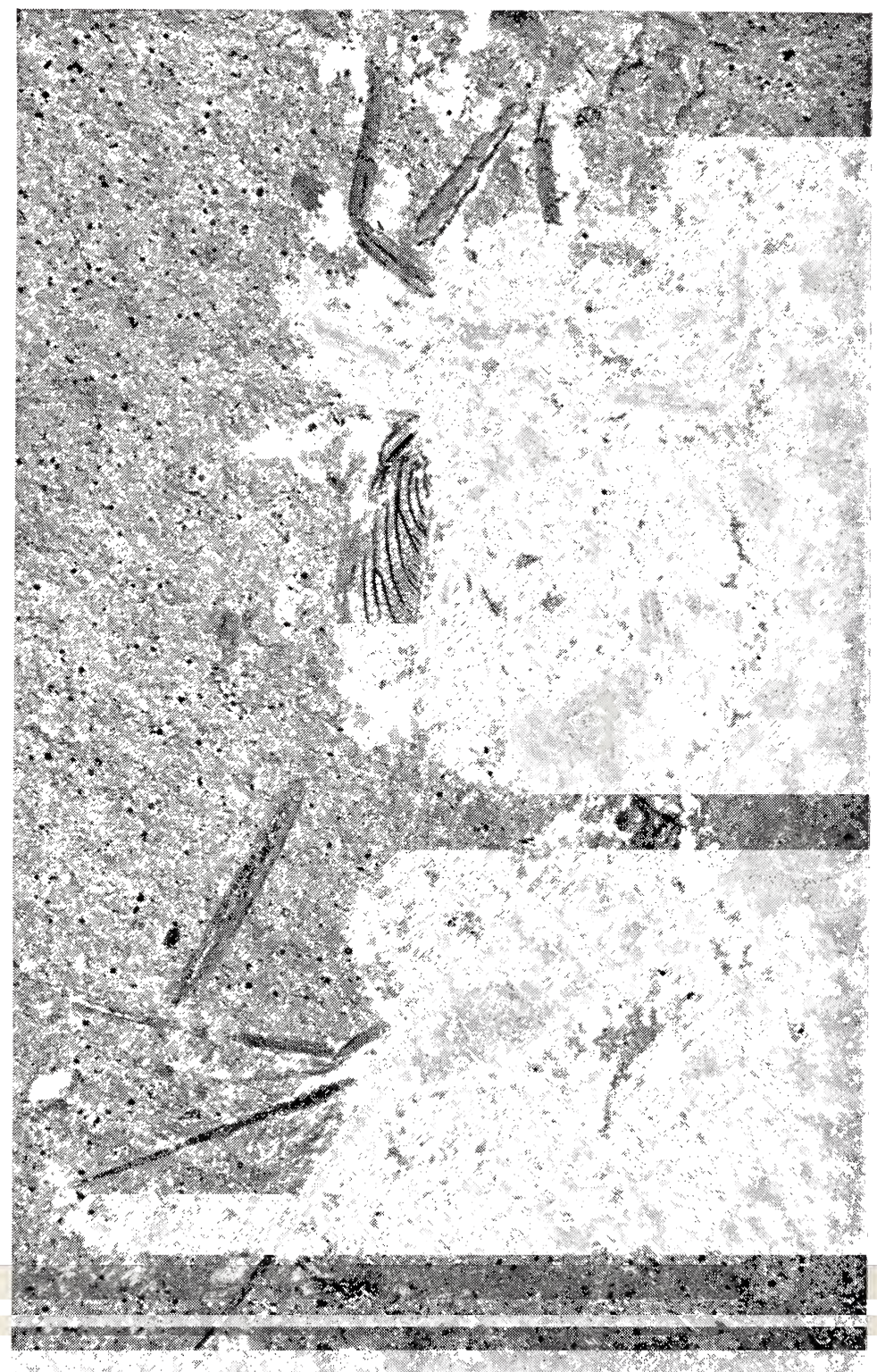

KUKALOVÁ - MAYFLY NYMPHS 
are preserved as distinct, dark lines and even the convexities or concavities of the veins are discernible. As shown in detail below, the venation of all but one of the nymphal wings is like that in the Permian family Protereismatidae and in particular like that of the genus Protereisma.

\section{Family Protereismatidae Lameere, I9I 7}

This widely distributed Permian family has been found in Permian deposits in Kansas, Oklahoma, the Soviet Union and Germany. The adults are characterized by having the fore and hind wing homonomous or nearly so; costal brace very well developed; Rs distinctly arising from $\mathrm{R}$ but coalesced shortly after its origin with MA for a short distance. The legs were very long and slender; the cerci were well developed and a median caudal filament was present.

Nymphs have not previously been described in this family. In this paper I am giving an account of several nymphs which have the venation of the wing pads like that of the wing of the adult Protereisma. One of the nymphs is from the Lower Permian strata of Noble County, Oklahoma (Midco), which contains several species of Protereisma known from adults; specific correlation of the nymph with any of these is impossible. The other nymphs discussed below are from the Lower Permian deposits in Moravia, in which only a single adult specimen, consisting of two overlapping wings, has been found; it is possible that the nymphs belong with this adult but there is no way of determining the probability of that correlation. For this reason specific names have not been assigned to any of the nymphal specimens.

\section{Protereisma sp. (nymph no. I)}

This specimen was collected at locality L-I 5 in the Midco member Wellington Formation, Noble County, Oklahoma, by F. M. Carpenter ( 1940$)$. In all probability this is a cast cuticle, although it is very well preserved with strong relief; it does, however, have the abrupt bend of the abdomen, characteristic of most of the nymphal specimens from Moravia, which look very much like cast cuticles. The following is a detailed account of this specimen (text-figures $\mathrm{I}$ and 2 ). Head slightly narrower than the prothorax; eyes probably of average size; mandibles large and very broad distally, with four prominent teeth; antennae very slender, segments subequal (length of antennae unknown). Prothorax about as broad as the mesothorax but only about half its length; anterior margin slightly concave; posterior markedly

Explanation of Plate 29

Photograph of Nymph No. 1, Lower Permian of Oklahoma. Length of fore wing pad, $5.3 \mathrm{~mm}$. Specimen no. 6311, Museum of Comparative Zoology. 


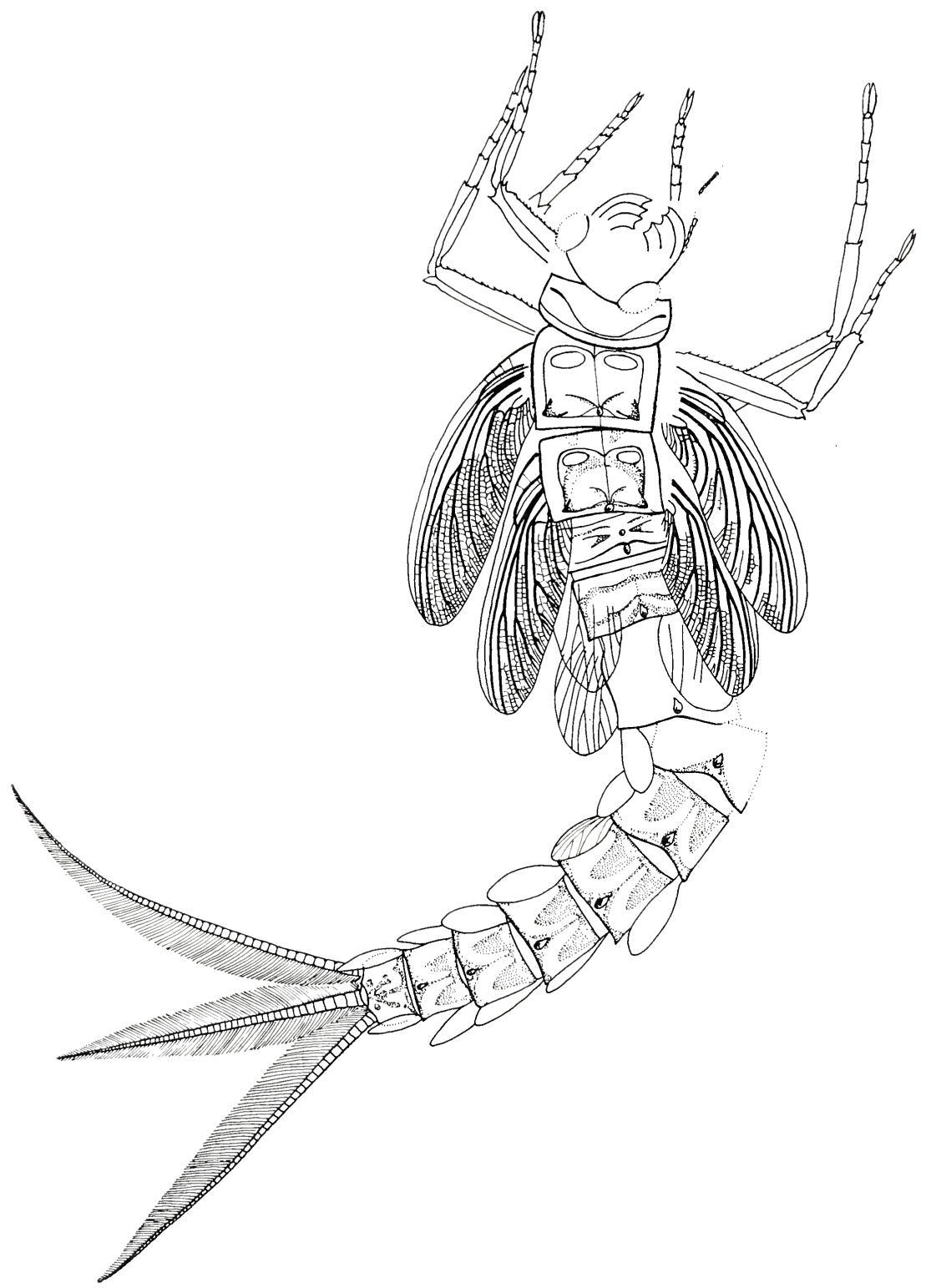

Fig. 1. Protereisma sp. (nymph no. 1), Lower Permian of Oklahoma. Original drawing. Claws of left middle leg and right hind leg figured from dorsal view. [Specimen in Museum of Comparative Zoology] 
half its length; anterior margin slightly concave; posterior markedly convex; a convex ridge extending transversely across the pronotum which also has a border along the posterior margin. Meso- and metathorax nearly equal; longitudinal suture strongly developed; each notum with a quadrate pigmented area with conspicuous swellings at attachment of leg muscles and with a pair of conspicuous spinelike projections in the latero-posterior regions; mesothorax slightly larger than metathorax. Legs subequal, with five distinct tarsal segments; tarsal segments with a row of spines; pretarsus with two nearly straight claws (from dorsal view shown in right leg of third pair) ; tibia slightly shorter than tarsus; femur longer and broader and armed on the ventral surface with a row of spines. Wing pads attached to the thorax only along the articular area (of the adult wing) and independent of each other, i.e., not enclosed in a common wing case, as in existing mayfly nymphs; the wing pads projecting posteriorly at an oblique angle from the body; wings nearly homonomous, the hind wing being slightly shorter; costal brace relatively much larger than in the adult wing; venation otherwise much as in the adult of Protereisma but MA independent from R and Rs basally; Rs clearly arising from $\mathrm{R}_{\mathrm{I}}$; cross veins somewhat more irregular and reticulate than in the adult. Abdomen slender, the segments apparently subequal, although the distortion of some segments prevents certainty of this statement; the posterior part of each segment has a prominent median projection, comparable to that found in the posterior part of the meso- and metathoracic segments; markings on the terga as shown in figure $I$; the cerci and the caudal filament arising from the posterior part of the tenth abdominal segment, the cerci with a dense row of long hairs projecting towards the caudal filament and the caudal filament with similar hairs on each side; gills of the first and second segments large but thin, showing a delicate series of lines as in the gills of some existing nymphs (e.g., Siphlonisca aerodromica Needham, as figured by Edmunds, Allen and Peters, I963, plate 5); remaining gills much smaller and showing fewer lines.

Dimensions: length of whole body, 2 I $\mathrm{mm}$; length of left forewing, $5.3 \mathrm{~mm}$; length of right caudal filament, $8.3 \mathrm{~mm}$; length of middle leg - femur, $4.0 \mathrm{~mm}$, tibia, $2.2 \mathrm{~mm}$; tarsus and pretarsus, $2.6 \mathrm{~mm}$.

In addition to this specimen, six other nymphs of mayflies from the same deposit in Oklahoma have been studied; these are much younger stages and are without wing pads but the body structures 

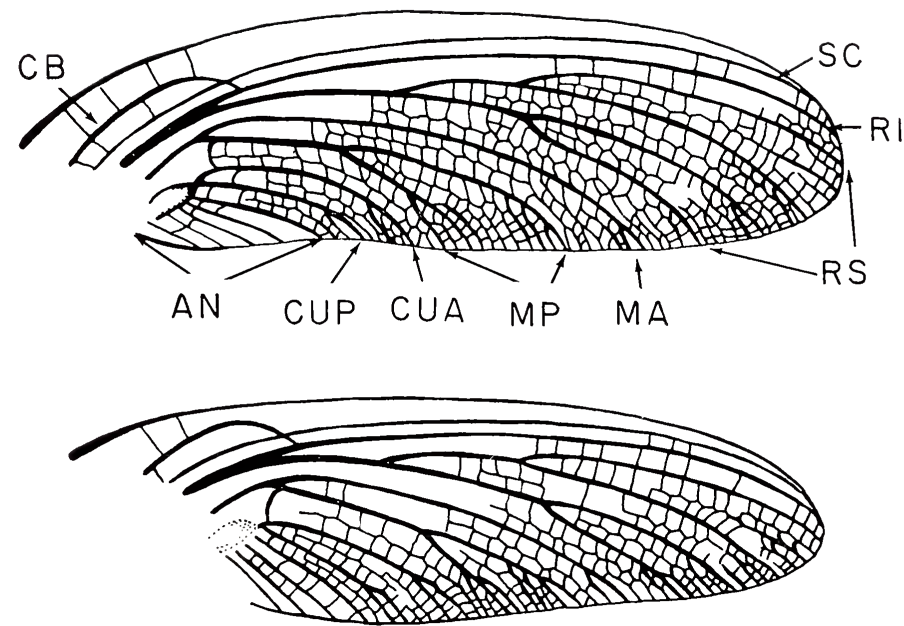

Fig. 2. Protereisma sp. (nymph no. 1), Lower Permian of Oklahoma. Original drawing. Left fore and hind wing.

\section{Protereisma sp. (nymph no. 2)}

seem to be the same as in the previous nymph. The insects could well be conspecific with the previous specimen.

This was collected in the Lower Permian of Obora, Moravia, in Czechoslovakia by Charles Havlata and is contained in the collection of Charles University in Prague. It is almost certainly a cast cuticle. Head not preserved; prothorax as broad as the metathorax or nearly so, its anterior margin straight, its anterior, lateral and posterior margins forming a smoothly convex border; otherwise as in nymph no. I. Mesothorax about one and a half times as long as the metathorax; both nota as in the previous nymph. Wing pads essentially as in nymph no. I, but even more divergent; wing venation also the same. Abdomen narrowing abruptly behind the sixth segment; first segment much shorter than segments two and three. Caudal filament and cerci of about the same length, reaching almost to about half the length of the abdomen. Tracheal gills are present on segments 2-9 (not preserved on first segment); gills apparently subequal and elongate oval in shape, but those on segments eight and nine are more narrow and lanceolate; gills with faint longitudinal lines, which are sometimes forked. Dimensions: length of the preserved part of body, $16.5 \mathrm{~mm}$; length of left forewing $5.2 \mathrm{~mm}$; length of left cercus, $5.7 \mathrm{~mm}$. 


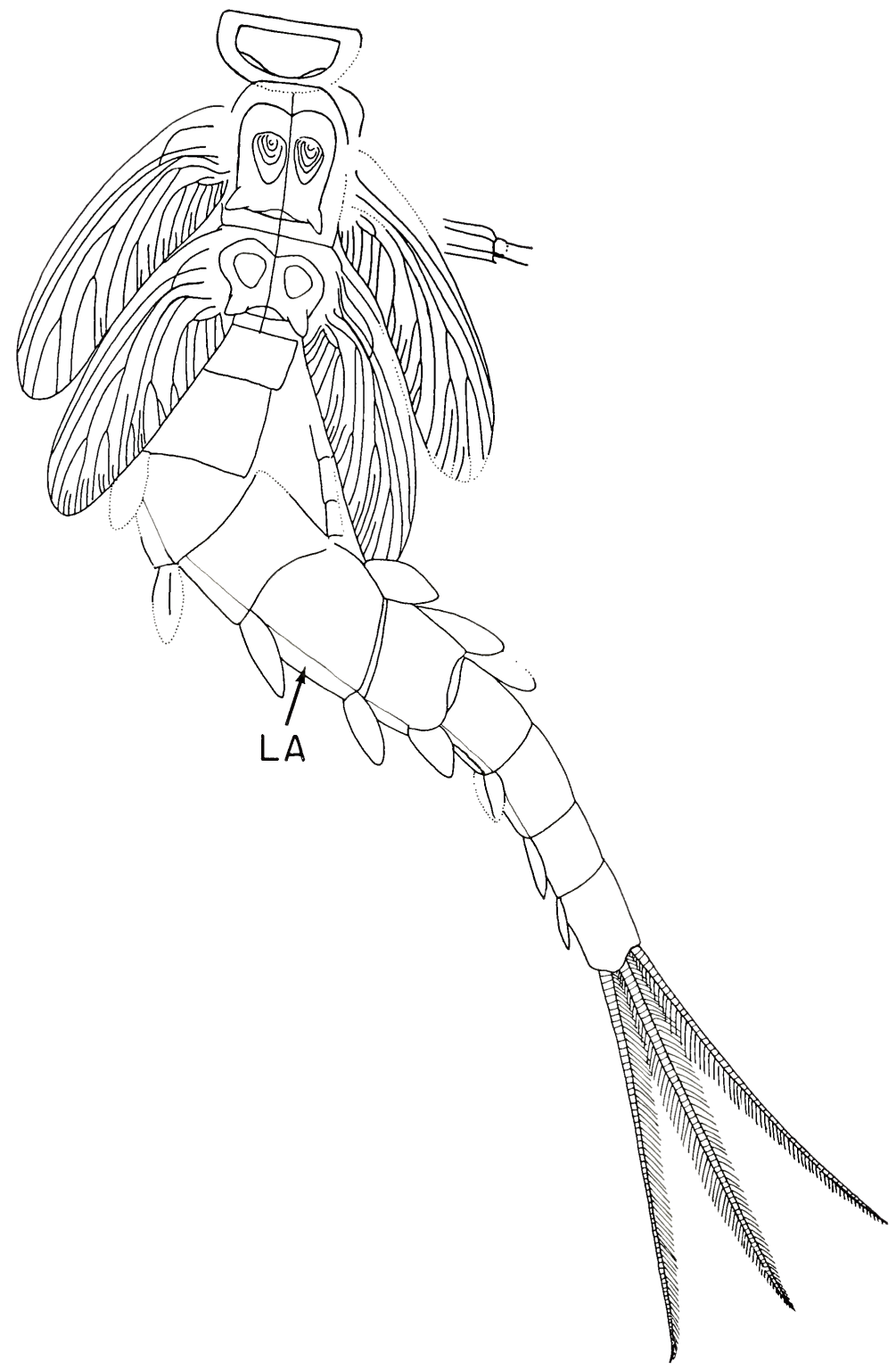

Fig. 3. Protereisma sp. (nymph no. 2), Lower Permian of Czechoslovakia. Original drawing. LA: lateral lamella. [Specimen in Charles University, Prague] 


\section{Protereisma sp. (nymph no. 3)}

This was also collected in the Permian of Obora, Moravia, Czechoslovakia and is contained in the collection of Charles University, Prague. It consists of a part of the thorax, including the wing pads. Prothorax relatively long and large being about as long as the mesothorax; anterior margin slightly concave; the side margins nearly parallel; the margined area is very distinct. Mesothorax about I.2 times as long as the metathorax. Wing pads independent and divergent, as in nymph no. I; venation very similar to that in the previously described nymphs; in both wings $\mathrm{Rs}$ arises distinctly from $\mathrm{R}$ but in the hind wing it appears to be connected to $M$ near the wing base by a cross vein. Dimensions: length of prothorax, $2.5 \mathrm{~mm}$; length of fore wing, $5.2 \mathrm{~mm}$; length of hind wing, $5.0 \mathrm{~mm}$.

\section{Protereisma sp. (nymph no. 4)}

This specimen is from the Lower Permian of Obora, Moravia, and is in the collection of Charles University. Prothorax much as in nymph no. 2 above but mesothorax seems relatively shorter; mesoand metanota as in the previous nymphs; legs with long femora. Wing pads similar in position and shape to those of the previous nymphs but venation very weakly indicated; the small size of these wing pads relative to the size of the thoracic segments shows that this is a much younger stage than that of nymph no. 2. Abdomen with segments $I$ and 2 somewhat narrower than the subsequent segments; markings on terga a little different from those of nymph no. I, as indicated in the figure; cerci and caudal filament with somewhat shorter hairs than in previous specimens; tracheal gills present on segments 2-9, not preserved on the first segment; those of the 9th segment very small. Dimensions: length of preserved part of body, $15.5 \mathrm{~mm}$; length of left fore wing about $2.5 \mathrm{~mm}$.

\section{Protereisma sp. (nymph no. 5)}

Lower Permian of Obora, Moravia. Prothorax as in the previous specimens but with the posterior border somewhat more rounded; otherwise as in nymph no. 2. Mesothorax broader and longer than the metathorax, both segments marked as in nymph no. 2. The legs are unknown. Wing pads as in previous nymphs ${ }^{2}$ and abdomen of usual form; cerci and caudal filament showing no hairs (probably due to a lack of preservation). Gills present on the first nine segments,

\footnotetext{
${ }^{2}$ The difference between the shape of the wings on the left and right side of the specimen is due to the unidirectional stress which subsequently affected the matrix clay.
} 
those on the first probably somewhat smaller than the others but the ones on the ninth pair much reduced. Dimensions: length of preserved part of body, I7.2 mm; length of left fore wing, $4.5 \mathrm{~mm}$; length of right fore wing, $5.3 \mathrm{~mm}$; length of right hind wing $5.0 \mathrm{~mm}$.

Discussion: the foregoing nymphs are sufficiently close structurally to indicate their membership in a single family; the nature of their wing venation indicates that this was most probably the family Protereismatidae. Their assignment to one genus is less certain but all have been placed in Protereisma since there are at present no

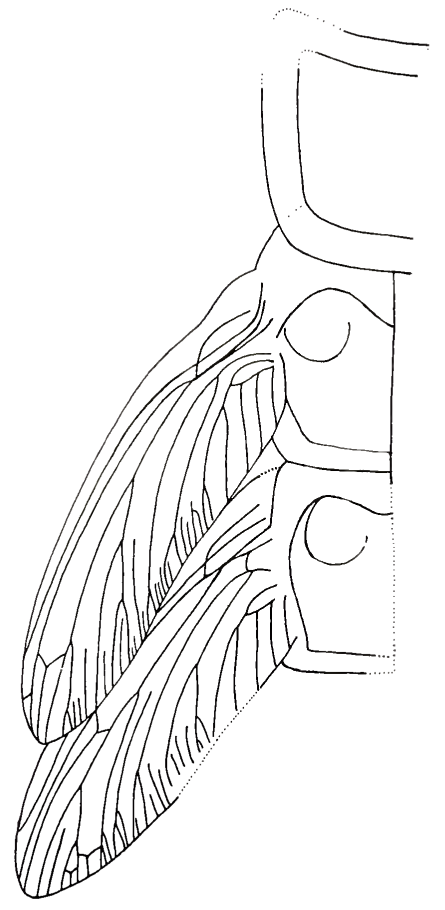

Fig. 4. Protereisma sp. (nymph no. 3), Lower Permian of Czechoslovakia. Original drawing. [Specimen in Charles University, Prague]

bases for recognition of genera among these Permian nymphs. From a survey of all of these specimens it is now possible to suggest characteristics possessed by the nymphs of the Protereismatidae. The head, preserved in only one nymph, was slightly narrower than the prothorax and rather long; the eyes were average size, the mandibles large with prominent teeth; the antennae very slender with numerous 
segments (total length unknown). The prothorax was about as broad as the metathorax but usually only about half the length of the mesothorax, with a nearly straight, or slightly concave anterior margin and rounded posterior-lateral margins. The meso- and metathoracic segments were subequal, the tibia shorter than the femur; the tarsi were 5-segmented and there were two nearly straight claws. The wing pads were divergent, independent from each other and not fused medially in young as well as older nymphs; they were attached to the thorax only along that part of the wing which becomes the articular region in the adult; the fore and hind wings were nearly equal, though the hind wing was slightly shorter; venation very similar to that of adult Protereisma but with MA clearly independent from Rs, and Rs distinctly arising from $\mathrm{R}_{\mathrm{I}}$; the costal brace was very strongly developed, more so than in the adults; the cross venation was much more reticulate than in the adults. The abdomen was slightly tapering, with the segmentation homonomous except that the first segment was somewhat shorter than the others; the cerci were only slightly longer than the median caudal filament; the latter had a dense row of hairs on each side and the cerci had similar hairs on the inner sides only.

In addition to the previous nymphs, which appear to belong to the family Protereismatidae, there is in the collection from Obora at Charles University one specimen of a nymph (nymph no. 6) which is very distinctive. It is almost certainly not a protereismatid but its family position cannot be determined; it probably represents a distinct family. Prothorax is formed much as in the previous nymphs, the anterior margin being straight but the meso- and metathoracic segments are relatively broader and shorter. The markings on the mesoand metanota are distinctly different from those of the previous nymphs, as shown in figure 7. Legs subequal, tibia much shorter than femur. Wing pads relatively short only about as long as the mesothorax is wide; these are widely separated on the thorax but not so divergent as in the preceding nymphs and they are distinctly widened towards the attachment at the thorax; the hind wings appear to be slightly shorter than the fore wings; the costal brace is not preserved and the venation is very indistinct but the costal and subcostal areas seem much narrower than in the Protereismatidae. The abdomen is relatively slender; segment I seems to be very short but it may be partially concealed under the metanotum. Gills are present on the first 7 segments and probably occurred on the 8th and 9 th but these segments are not preserved in the fossil; the gills are very long, fully twice as long as any segment. The cerci and caudal 


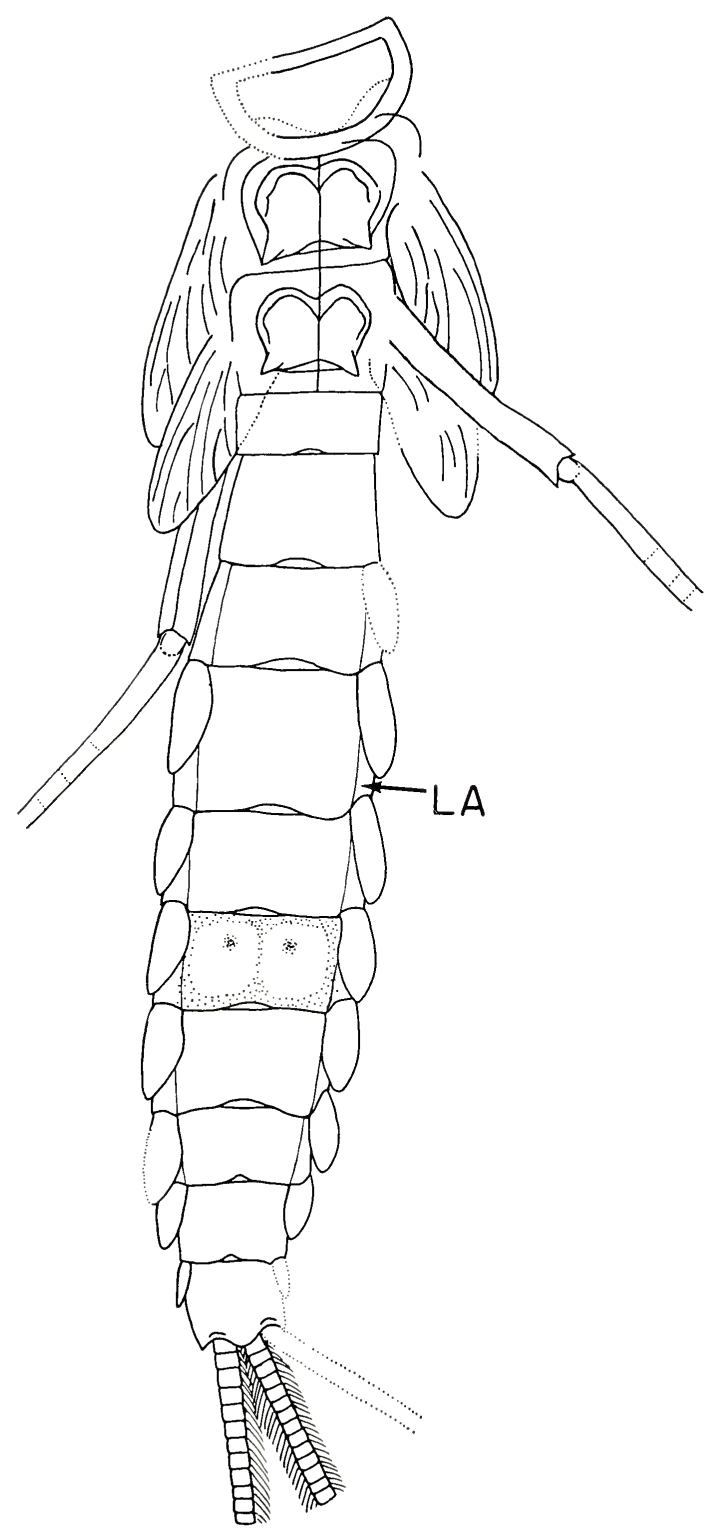

Fig. 5. Protereisma sp. (nymph no. 4), Lower Permian of Czechoslovakia. Original drawing. LA: lateral lamella. Younger stage of a nymph. [Specimen in Charles University, Prague] 


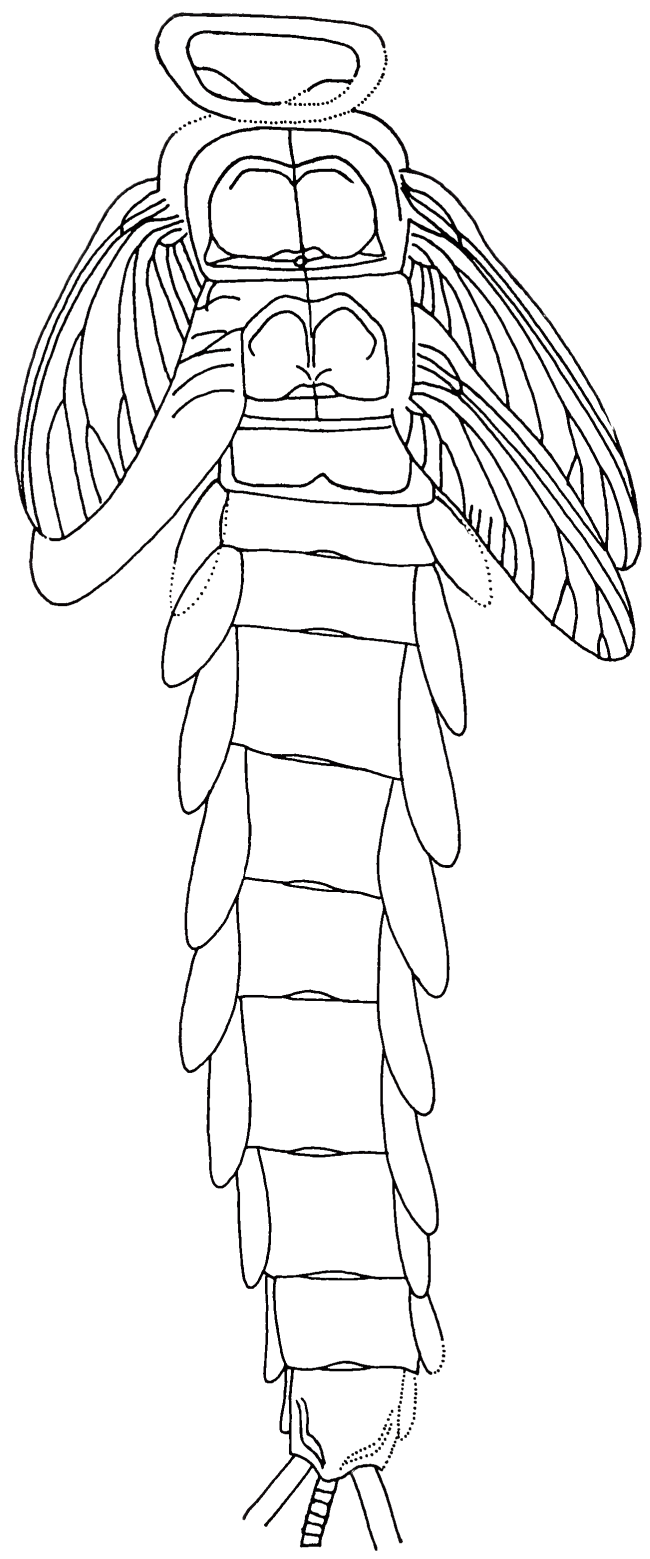

Fig. 6. Protereisma sp. (nymph no. 5), Lower Permian of Czechoslovakia. Original drawing. Lamellae narrow, hidden under gills. [Specimen in Charles University, Prague] 
filament are not preserved. Dimensions: length of preserved body, I $2.6 \mathrm{~mm}$; length of left forewing, I. $8 \mathrm{~mm}$.

The Permian nymphs considered above present some interesting and unexpected features. Most striking, of course, is the position and nature of attachment of the wing pads. The evidence is clear that in these nymphs the developing wings projected away from the thorax, that they were attached to the thorax only along the articular region, and that they were independent of each other. That this condition of the wing pads was not confined to the mature nymphs or transitional to the subimago is shown by its presence in the early instars. This is especially significant in view of the equally independent and even more lateral position of the wing pads in the Megasecoptera described by Carpenter and Richardson (1968, this issue of Psyche). The indications are that in the earliest Ephemeroptera the wings developed in that way, and that the position of the developing wings in Recent mayflies, i.e., fastened back over the thorax, is a derived one. Indeed, the longitudinal position of the wings might well be an adaption to the aquatic environment - a streamlining of the body form. ${ }^{3}$

The geological record of the mayfly nymphs is too meagre to show transitions from the oblique position to the posterior position of the wing pads, but the Triassic nymph which Handlirsch (1918) described as Mesoplectopteron longipes certainly has the wings more oblique than in any existing species ${ }^{4}$ although less so than in Protereisma.

The presence of more posteriorly directed wing pads in one of the Permian nymphs (no. 6) described above (but not a protereismatid) suggests that loss of the divergent nymphal wings occurred independently in several lines of the Ephemeroptera.

Another interesting feature is the strong development of the costal brace. This is well-developed in the adult Protereismatidae but

\footnotetext{
${ }^{3}$ It is pertinent to point out in this connection that Dr. George Edmunds has informed me that the wing pads of some species of the Recent family Siphlonuridae, which is generally recognized as the most primitive of the living families of mayflies, show more divergence than those of any other living family and that they have a more narrow basal attachment.

${ }^{4}$ The figure of Ephemeropsis orientalis, from the Jurassic of Siberia, is depicted by Brauer, Redtenbacher and Ganglbauer (1889, plate 1, fig. 4) as having wing pads in a slightly oblique position, but the more detailed figures of Ephemeropsis given by Meshkova (1961) shows the wing pads straight back, as in Recent nymphs. Handlirsch has stated (1904) that the Permian nymphs, Phthartus rossicus and P. netschajevi, had slightly divergent wing pads, but he attached no evolutionary significance to their position.
} 


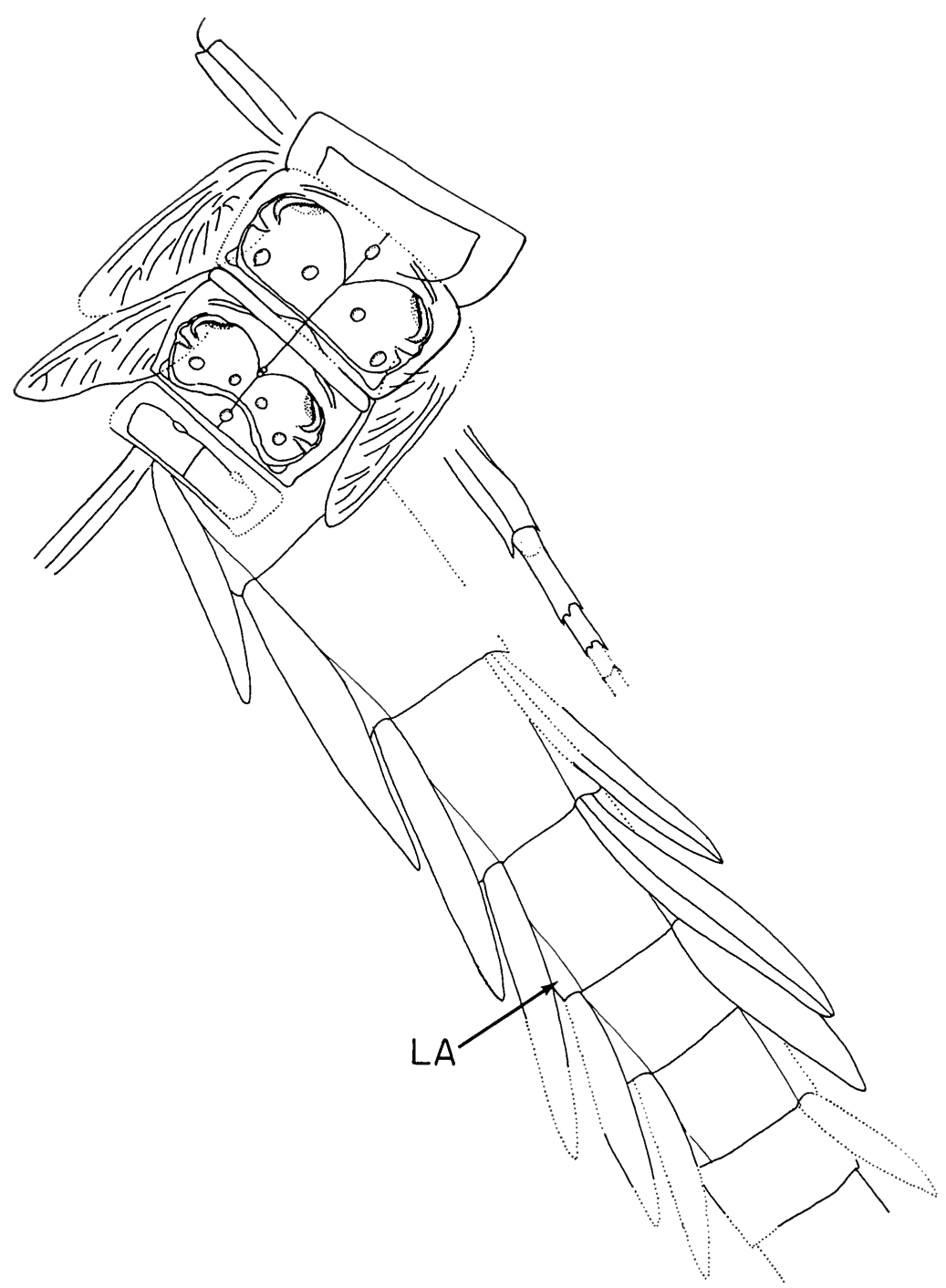

Fig. 7. Ephemeroptera inc. fam. (nymph no. 6), Lower Permian of Czechoslovakia. Original drawing. LA: lateral lamella. [Specimen in Charles University, Prague] 
it is much more conspicuous in the nymphs. In Recent adults and nymphs, it is very small in even the most primitive families. Its significance has long been a puzzle. However, in view of the structure of the Permian nymphal wings, a possible function for the brace in the nymphs needs to be considered; it may well have been a strengthening structure for the nymphal wings, which in the protereismatids extended outward from the body without much other support and which might have been carried over in vestigial form to the adults. In the more highly evolved nymphs, as the wing pads developed along the body, the support of the brace may have no longer been needed.

Still another notable feature of these Permian nymphs is the nature of the legs, especially the tarsal segmentation. In the adults of Protereismatidae, so fas as known, the legs were exceptionally long and slender, possessed five tarsomeres, and a pair of long pretarsal claws. They are not very different, except for their length, from those of living adults, in which the number of tarsomeres ranges from 5 to I. The legs of the protereismatid nymphs, although shorter than those of the adults are basically similar to them in structure, with 5 tarsomeres and two slightly curved pretarsal claws. ${ }^{5}$ In contrast, the legs of Recent mayfly nymphs are modified for swimming and have only partially divided tarsi; so in nearly all species there are only one or two tarsomeres and there is only one claw. The cursorial legs of the protereismatid nymphs clearly show that they were not active swimmers and suggest that they walked actively along the bottom of ponds or streams.

In contrast to the legs, the tracheal system of the protereismatid nymphs was highly modified for an aquatic environment. Especially surprising is the presence of tracheal gills along the first to the ninth abdominal segments; in living nymphs the gills do not extend beyond the seventh segment, at most. It is interesting to note, also, that the few Permian nymphs known show considerable variation in the form of the gills. In the specimen from Oklahoma (nymph no. I) the first two pair are much enlarged and resemble somewhat the opercula that occur in some Recent nymphs; in those from Moravia the gills on any one nymph appear very much alike. In one of the Moravian nymphs (no. 6) they are much longer and more slender, without differentiation of the anterior pairs. It is possible that some of these

\footnotetext{
${ }^{5}$ The five tarsomeres do not appear to be adult structures visible through the nymphal cuticle. As noted above, these fossil nymphs almost certainly consist of cast cuticles; furthermore, the tarsomeres are present in some of the young nymphs from Moravia. For the same reasons, the pretarsal claws are not regarded as adult structures seen through the nymphal cuticle.
} 
differences are due to different stages of development, but in any case the respiratory system of the nymphs was clearly highly adapted for an aquatic life. In this connection, reference should be made to the presence of lamellae along the sides of the abdominal segments. In Recent nymphs the lamellae occur at the junction of the terga and sterna, extending outward and forming flat, plate-like ridges along the pleural region of the segments. In those protereismatid nymphs which show the pleural region of the segments lamellae appear to be present, also. They may be homologous with similar structures which have been known for many years along the sides of the abdomen of adult Paleodictyoptera and Megasecoptera and which have often been interpreted as persistent, vestigial gills.

The cerci and the caudal filament of the protereismatid nymphs are strikingly like those of some Recent mayflies, even to the arrangement of the long hairs. There appear to have been no basic changes in the nature of these structures since Permian times, except in a few of the most highly specialized Recent genera.

The mandibles are unfortunately known in only one nymph (Oklahoma nymph no. I). In that specimen they are surprisingly large and broad, with well-developed teeth. The mandibles of existing mayfly nymphs are diversely adapted but none appear to be as large or as massive as those of the fossil. In all probability protereismatids were predaceous.

In summary, it can be stated that the Permian protereismatid mayfly nymphs (so far as known) were adapted for aquatic life, having well-developed gills on the first nine abdominal segments; that they had walking instead of swimming legs, with five segmented tarsi, and that the nymphal wings developed in a lateral-posterior position, being connected to the thorax only along the articular region of the wing.

\section{REFERENCES}

Brauer, F., J. Redtenbacher and L. Ganglbauer

1889. Fossile Insekten aus der Juraformation Ost-Sibiriens. Mem. de l'Acad. Imp. Sci. St. Petersburg, 7 ser. $36(15):$ 1-20.

\section{Carpenter, F. M.}

1933. The Lower Permian Insects of Kansas. Part 6. Proc. Amer. Acad. Arts Sci., 86:411-503.

1947. Lower Permian Insects from Oklahoma. Part 1. Proc. Amer. Acad. Arts Sci., 76: 25-54.

1963. Studies on Carboniferous Insects from Commentry, France. Part IV. The Genus Triplosoba. Psyche, 70(2): 120-128.

Clemens, W. A.

1915. Mayflies of the Siphlonurus Group. Can. Ent., 47: 245-260. 
Edmunds, G. F., Jr., R. K. Allen and W. L. Peters

1963. An Annotated Key to the Nymphs of the Families and Subfamilies of Mayflies (Ephemeroptera). Univ. Utah Biol. Ser., $13(1): 1-55$.

HandLIRSCH, A.

1904. Uber einige Insektenreste aus der Permformation Russlands. Mem. de l'Acad. Imp. Sci. St. Petersburg, 8 ser. 16(5): 1-7.

1918. Bericht der Sektion fur Zoologie. Fossile Ephemeridenlarven aus dem Bundsandstein der Vogesen. Ver. zool.-bot. Ges. Wien, 1-3.

1925. Palaeontologie, in Schröder, Handbuch der Entomologie, 3: 117306.

Haughton, S. H.

1924. Fauna and Stratigraphy of the Stormberg Series in South and Central Africa. Ann. S. Afr. Mus., Cape Town, 12:323-497.

Mesh kova, N. P.

1961. On the Nymphs Ephemeropsis trisetalis Eichwald (Insecta). Paleont. Journ. USSR, 1961, No. 4, 164-168.

Tshernova, O. A.

1961. Systematic Position and Geological Age of Mayflies of the Genus Ephemeropsis Eichwald (Ephemeroptera, Hexagenitidae). Ent. Oboz., 40: 858-869.

1965. Some Fossil Mayflies (Ephemeroptera, Misthodotidae) from Permian beds of the Ural. Ent. Oboz., 44: 353-361.

1967. May-fly of the Recent Family in Jurassic Deposits of TransBaikalia (Ephemeroptera, Siphlonuridae). Rev. Ent. URSS, 46: 322-326. 


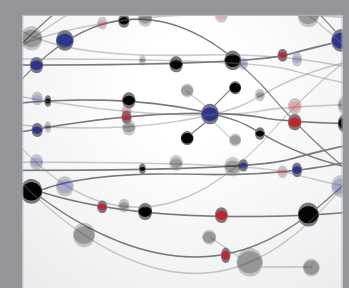

The Scientific World Journal
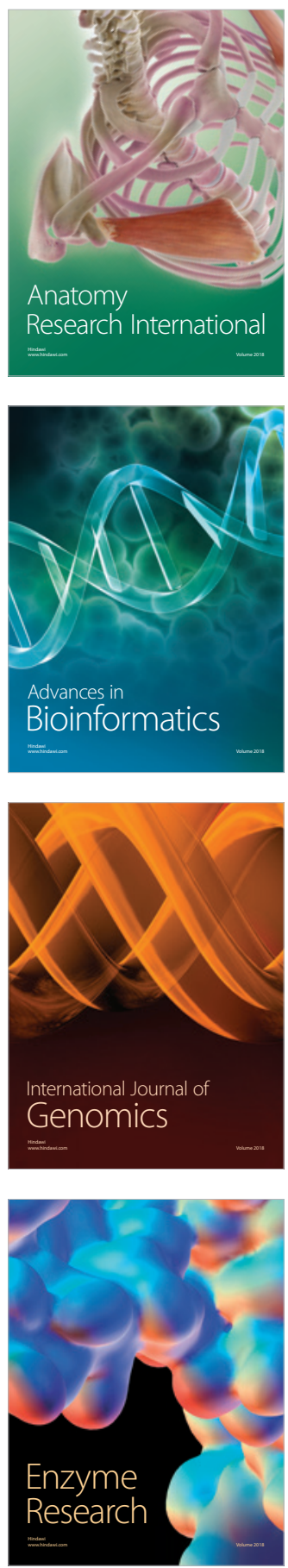
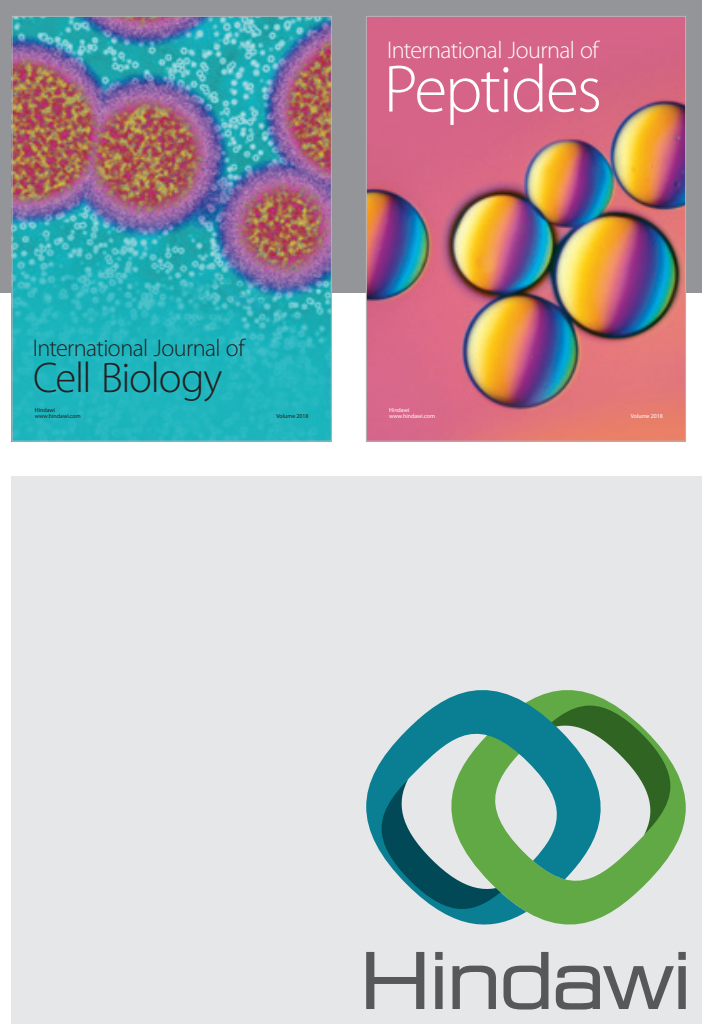

Submit your manuscripts at

www.hindawi.com
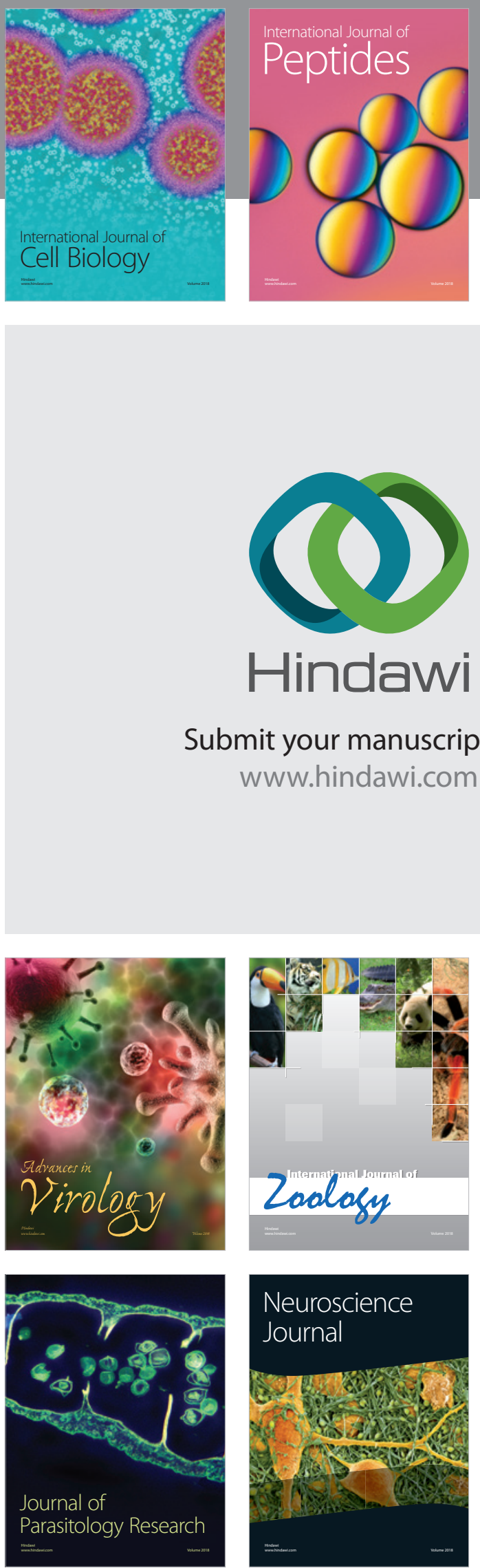
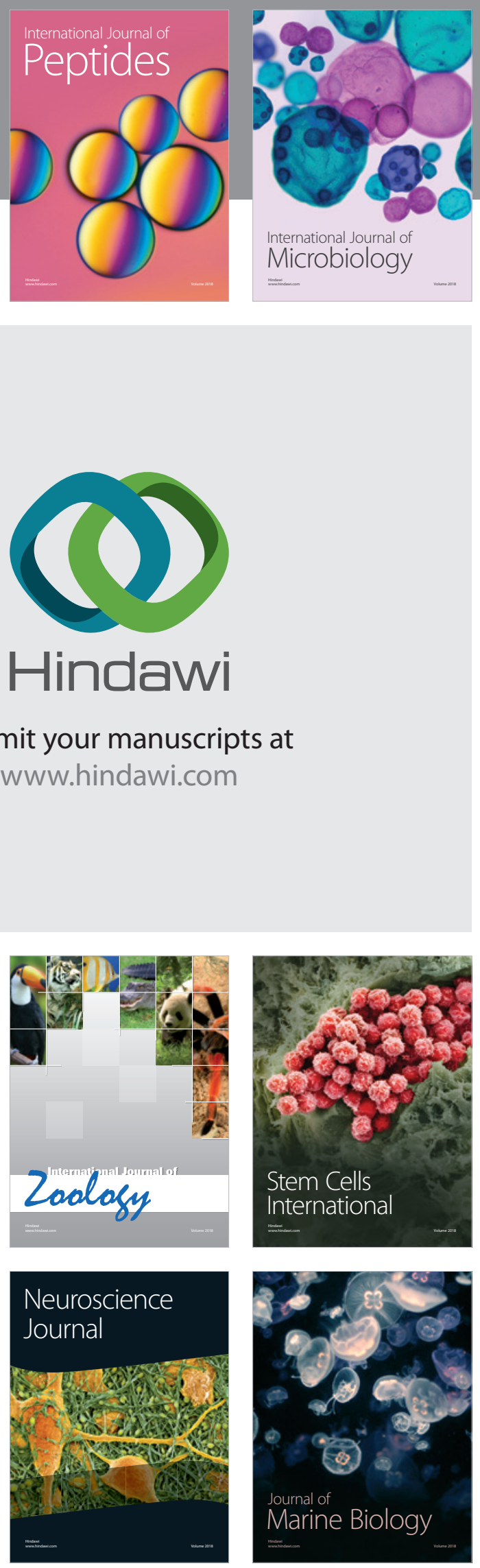
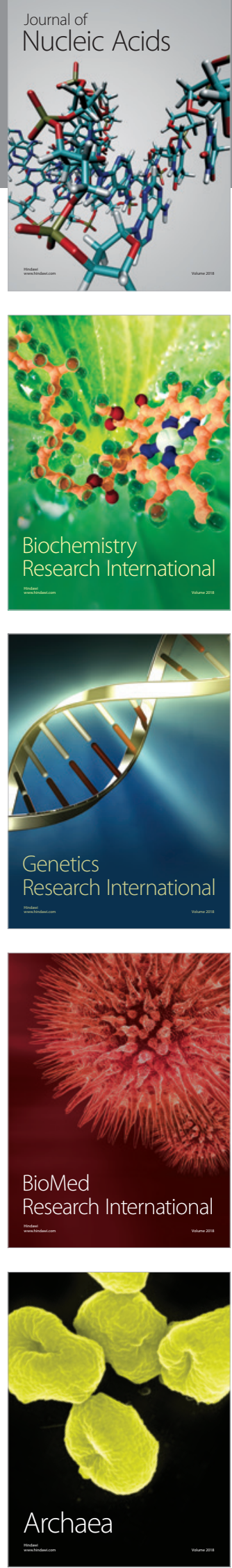